\title{
Topical treatment with Xiaozheng Zhitong Paste alleviates bone cancer pain by inhibiting proteinase-activated receptor 2 signaling pathway
}

\author{
YANJU BAO $^{1}$, GAIMEI WANG $^{2}$, YEBO GAO $^{1,3}$, MAOBO DU $^{4}$, LIPING YANG $^{5}$, \\ XIANGYING KONG ${ }^{4}$, HONGGANG ZHENG ${ }^{1}$, WEI HOU ${ }^{1}$ and BAOJIN HUA ${ }^{1}$ \\ ${ }^{1}$ Department of Oncology, Guang'anmen Hospital, China Academy of Chinese Medical Sciences, Xicheng, Beijing 100053; \\ ${ }^{2}$ Department of Gynecology, the Third Hospital of Zhengzhou, Zhengzhou, Henan 450000; ${ }^{3}$ Beijing University of \\ Chinese Medicine, Chaoyang, Beijing 100029; ${ }^{4}$ Institute of Chinese Materia Medica, China Academy of \\ Chinese Medical Sciences, Dongzhimen, Beijing 100700; ${ }^{5}$ Department of Nephrology, Guang'anmen \\ Hospital, China Academy of Chinese Medical Sciences, Xicheng, Beijing 100053, P.R. China
}

Received April 23, 2015; Accepted June 2, 2015

DOI: $10.3892 / o r .2015 .4073$

\begin{abstract}
Herbal analgesic Xiaozheng Zhitong Paste (XZP) and related modifications are often used in traditional Chinese medicine to manage cancer pain. However, its underlying mechanism remains unknown. To investigate the effects and mechanism of XZP on bone cancer pain in a rat model of breast cancer-induced bone pain, a bone cancer pain model was established by inoculating Walker 256 cells into Wistar rats. Bone cancer-bearing rats were topically treated with different doses of XZP or injected with $5 \mathrm{mg} / \mathrm{kg}$ of osteoprotegerin (OPG) as positive control. Bone destruction, bone mineral content (BMC) and bone mineral density (BMD) were analyzed by radiology. Paw withdrawal threshold (PWT) and paw withdrawal latency (PWL) were examined to determine pain levels. Trypsin, TNF- $\alpha$ and IL- $1 \beta$ serum levels were determined using enzyme-linked immunosorbent assay (ELISA). Central sensitization markers such as c-Fos, GFAP, IBA1 and CGRP, as well as proteinase-activated receptor 2 (PAR2) signaling pathway mediators such as PAR2, PKC- $\gamma$, PKA and TRPV1, were determined by quantitative RT-PCR and western blotting assay. XZP treatment significantly mitigated bone cancer-related nociceptive behavior, bone damage, $\mathrm{BMC}$ and $\mathrm{BMD}$; and decreased radiological scores in rats. XZP treatment significantly inhibited IBA1, GFAP, c-Fos and CGRP expressions in the spinal cord; and significantly mitigated trypsin, TNF- $\alpha$ and IL- $1 \beta$ serum levels. Furthermore, PAR2, PKC- $\gamma$, PKA and TRPV1 relative mRNA levels and
\end{abstract}

Correspondence to: Dr Baojin Hua or Dr Yanju Bao, Department of Oncology, Guang'anmen Hospital, China Academy of Chinese Medical Sciences, Beixiange 5, Xicheng, Beijing 100053, P.R. China E-mail: huabaojin2008@126.com

E-mail: baoyanju@126.com

Key words: Xiaozheng Zhitong Paste, traditional Chinese medicine, bone cancer pain, PAR2 signaling pathway protein expression in bone lesions were significantly reduced in rats treated with XZP. XZP significantly alleviates breast cancer-induced bone pain by inhibiting the PAR2 signaling pathway.

\section{Introduction}

Primary and metastatic bone cancers are often accompanied by severe pain. Bone cancer pain occurs in $75-90 \%$ of patients with metastatic cancer (1) and is often debilitating and intractable, affecting the quality of life of patients $(2,3)$. Bone cancer pain is associated with breakthrough pain, which is defined as 'a transitory exacerbation of pain experienced by patients who have relatively stable and adequately controlled baseline pain' (2). Hence, controlling bone cancer pain would be of great significance in the management of patients with bone cancer.

Currently, there are many therapeutic options available for alleviating bone cancer pain including external beam radiotherapy, local surgery, opioid analgesia, non-steroidal anti-inflammatory drugs (NSAIDs), bisphosphonates and other anesthetic techniques (4). However, these therapies either have poor responses or require high dosages that are often associated with severe adverse effects (5-8). For instance, although bisphosphonates are effective in reducing skeletal morbidity from bone metastases and bone cancer pain, their efficacy remains unclear $(9,10)$. Therefore, there is an urgent need for the discovery and development of new therapeutic reagents to control bone cancer pain, particularly for breakthrough pain.

We and other researchers have shown that some Chinese herbal medicines have potent antinociceptive activity, and could effectively control cancer pain including bone cancer pain in clinical practice (11-14). Indeed, it is reported that $\sim 41-62 \%$ of cancer patients use herbs as a complementary or alternative medical therapy for cancer pain management (15). Topical treatment is an attractive and effective option, particularly for bone cancer pain management; since oral administration of herbal medicines causes several side-effects 
such as nausea, vomiting and diarrhea, affecting the quality of life of patients $(11-13,16)$. Xiaozheng Zhitong Paste $(X Z P)$ is a herbal analgesic paste that is prepared from six herbs including Xuejie (Dragon's blood), Yanhusuo (Corydalis Rhizoma), Ruxiang (Olibanum), Moyao (Myrrha), Qingdai (Natural Indigo) and Bingpian (Borneolum Syntheticum). Our previous studies showed that XZP significantly alleviated cancer pain including bone cancer pain in patients with middle and late stages of cancer $(16,17)$. However, its underlying mechanism has not been systemically explored.

Specific cellular and molecular mechanisms underlying bone cancer pain remain largely obscure $(18,19)$. While several lines of studies have demonstrated remarkable sensitization of peripheral nociceptors in bone, resulting from the tumorinduced acidosis and cytokine synthesis; emerging evidence indicates that central sensitization exists in the spinal dorsal horn of a rodent model of bone cancer pain such as the activation of astrocytes (20-22) and altered glutamatergic synaptogenesis $(23,24)$.

Proteinase-activated receptors (PARs) are a family of the $\mathrm{G}$-protein coupled receptors that are activated by proteases, which liberates a tethered ligand by cleaving the N-terminus of the receptors initiating several intracellular signal pathways (25). Among the four PAR subtypes, PAR1, PAR3 and PAR4 are preferentially activated by thrombin, while PAR2 is preferentially activated by trypsin and trypsin-like proteinases $(26,27)$. All four PARs are expressed throughout the peripheral and central nervous system (26-33). In the spinal dorsal horn, PAR2 receptors are located in the microglia, astrocytes, neurons and terminals of afferent fibers originating from dorsal root ganglions (26). Previous studies have demonstrated the critical involvement of PAR2 in the pathogenesis of several types of inflammatory or neuropathic pain (26). Activation of PAR2 signaling participates in the induction of peripheral nociceptor sensitization in a rodent model of bone cancer pain (34). We have also demonstrated that the activation of PAR2 signaling contributes to the central sensitization in rats with bone cancer pain $(26,27)$. However, there is no information on the impact of XZP treatment on peripheral and central sensitization, and on the PAR2 signaling pathway. Given that XZP effectively alleviates bone cancer pain, we hypothesized that XZP treatment inhibits the PAR2 signaling pathway; mitigating peripheral and central sensitization. The present study was designed to test this hypothesis, utilizing a rat model of bone cancer nociception to evaluate the therapeutic effect of XZP on bone cancer pain and explore its potential underlying mechanism. We believe that our results have an impact on the development of XZP as an effective topical treatment for bone cancer pain, and future discoveries of novel PAR2-targeted therapy for cancer pain in general.

\section{Materials and methods}

$X Z P$ preparation. $\mathrm{XZP}$ is composed of the six aforementioned traditional Chinese medicines. High performance liquid chromatography (HPLC) analysis has shown that XZP contained tetrahydropalmatine $(0.0568 \%)$, imperatorin $(0.0041 \%)$, isoimperatorin $(0.0122 \%)$, coptisine $(0.0358 \%)$ and palmatine chloride $(0.112 \%)$ (16).
Animals. Animal use and care protocols were reviewed and approved by the Animal Care and Use Committee of the China Academy of Chinese Medical Sciences, Beijing, China. All animal studies were carried out in accordance with the guidelines of the International Association for the Study of Pain (35). Female Wistar rats, weighing 150-180 g, were obtained from the Department of Experimental Animal Sciences, Peking University Health Science Center (Beijing, China). Individual rats were housed in specific pathogen-free $(\mathrm{SPF})$ facilities under strict temperature $\left(24 \pm 1^{\circ} \mathrm{C}\right)$ and humidity $(60 \%)$ control on a $12 / 12 \mathrm{~h}$ light/dark cycle with free access to standard food and tap water.

Rat bone cancer pain model and XZP treatment. Wister rat Walker 256 breast sarcocarcinoma cells were prepared, and a rat bone cancer pain model was established as previously reported (32). Briefly, Wistar rats were intraperitoneally (i.p) injected with Walker 256 cells $\left(2 \times 10^{7}\right.$ in $0.5 \mathrm{ml}$ of Hank's solution). Seven to 14 days later, cells in the produced ascites were collected. After being anesthetized, 50 rats were injected with $10^{5}$ Walker 256 cells in $10-\mu 1$ of Hank's solution into the left tibia of the hind paw. Then, the injection site was covered by bone wax and the wound was closed. Sham control rats $(n=10)$ received the same surgery and volume of vehicle injection. All rats were subjected to the same post-operative care.

Rats with bone cancer were randomly divided into five groups ( $n=10 /$ group): one placebo control group, topically treated with inert paste; three XZP groups, treated with low $(15.75 \mathrm{~g} / \mathrm{kg})$, medium $(31.5 \mathrm{~g} / \mathrm{kg})$ and high $(63 \mathrm{~g} / \mathrm{kg})$ doses of XZP; one OPG group, subcutaneously injected with $5 \mathrm{mg} / \mathrm{kg}$ of OPG twice per day. Sham control rats were also topically treated with inert paste. XZP and placebo pastes were evenly applied on the skin of tumor-bearing tibias; which were then covered with gauze and a layer of plastic film, sealed and fixed with desensitized adhesive plaster. Treatments were performed twice a day at 8:00 am and 20:00 pm for a total of 21 days, beginning at day one after cancer cells were implanted into the tibias (17).

Radiological analysis of bone lesions. Cancer-related osteolytic lesions in rat tibias were examined by X-ray radiology at day 21 after cell inoculation. Rats were anaesthetized with sodium pentobarbital $(45 \mathrm{mg} / \mathrm{kg})$ by i.p injection and exposed to X-ray (Emerald 125) at $40 \mathrm{kVp}$ for $1 / 20 \mathrm{sec}$. X-ray film (Henry Schein blue sensitive film; Shanghai Han Ruixiang Trade Co., Ltd.) was developed with a film developer (Konica SRX-101; Suzhou Zhongyi Electronic Technology Co., Ltd.). Tibias were scanned and reconstructed with an isotropic voxel size of $8-\mu \mathrm{m}$ on a micro-CT system (eXplore Locus SP; GE Medical Systems, Zhongtong Shanghai Automation \& Electrics Co., Ltd.). Reconstructed 3D images of femurs were analyzed using Microviewer (GE Medical Systems, Zhongtong Shanghai Automation \& Electrics Co., Ltd.) as previously described (36). Bone mineral density (BMD) of left tibias in individual rats were measured by dual energy X-ray absorptiometry using a PIXImus Mouse Densitometer; and bone mineral contents were calculated using small animal analysis software (both from GE Lunar Medical System, Zhongtong Shanghai Automation \& Electrics Co., Ltd.) at day 21, after cell inoculation. 
Determination of mechanical threshold and paw withdrawal latency. The effects of XZP treatment on spontaneous nociceptive behavior were determined using mechanical threshold and paw withdrawal latency (PWL), as previously described $(11,16,27,28,30,32)$. In brief, individual rats were placed in an inverted plastic chamber on the glass surface of a Paw Thermal Stimulator System (UCSD, San Diego, CA, USA) for $30 \mathrm{~min}$ before the test. Mechanical hyperalgesia was measured using a single rigid filament attached to a handheld transducer (automatic plantar analgesia tester; Institute of Biomedical Engineering, Chinese Academy of Medical Science, Tianjin, China). Animals were acclimated to their surroundings daily for $10 \mathrm{~min}$ for three consecutive days in a plexiglass box on a metal grid surface prior to testing. On testing days, rats were allowed to acclimate for 5-10 min. A rigid filament was pressed perpendicularly against the medial plantar surface of the hind paw with increasing force. Brisk paw withdrawal or paw flinching accompanied by head turning, biting and/or licking upon application of the increasing force was considered as a positive response. Paw withdrawal threshold (PWT) was defined as the minimal force (g) required in evoking the cited positive responses. Each hind paw was tested three times and data were averaged. Interval between consecutive tests of the same paw was $5 \mathrm{~min}$. The same procedure was performed on day 3, 6, 9, 12, 15, 18 and 21 after cell inoculation. Each hind paw was stimulated with a focused beam of radiant heat using an analgesiometer (37360; Ugo Basile, Italy) underneath the glass surface. When the paw was withdrawn from the stimulus, PWL was automatically recorded to the nearest $0.1 \mathrm{sec}$. Stimuli intensity was adjusted to generate an average baseline PWL of $\sim 10.0 \mathrm{sec}$ in naive animals. Maximum stimulation was controlled to $<20 \mathrm{sec}$ to prevent potential tissue damage. Paws were alternated randomly to preclude 'order' effects. Individual rats were subjected to four tests with 5-min intervals before surgery; and 2, 5, 8, 11, 14, 17 and 20 days after cell inoculation. Mean PWL values were calculated for each time point for individual rats.

Histological evaluation. Rats were deeply anesthetized by pentobarbital and transcardially perfused with saline on day 0 and 21 after inoculation ( $n=8 /$ group). The left tibia of each rat was dissected, fixed in $10 \%$ formalin overnight, decalcified in $15 \%$ EDTA-phosphate-buffered saline (PBS) for seven days and paraffin-embedded. Tissue sections $(6-\mu \mathrm{m})$ were prepared and stained with hematoxylin and eosin ( $\mathrm{H} \& \mathrm{E})$ for pathological analysis.

Analysis of trypsin, TNF- $\alpha$ and IL-1 $\beta$ serum by enzymelinked immunosorbent assay (ELISA). Orbital venous blood samples from each rat were collected on day 0,7 , 14 and 21 after cell implantation. Inflammatory mediator levels were determined using ELISA kits (Beijing Jia Mei Nuo Si Biotechnology Co., Ltd.; trypsin, ng/ml, catalog no. ABIN1117631, detection range $0.16-10 \mathrm{ng} / \mathrm{ml}$, detection minimum $0.09 \mathrm{ng} / \mathrm{ml}$; interleukin- $1 \beta, \mathrm{pg} / \mathrm{ml}$, catalog no. ABIN365189, detection range 62.5-4,000 pg/ml, detection minimum $62.5 \mathrm{pg} / \mathrm{ml}$; tumor necrosis factor- $\alpha, \mathrm{pg} / \mathrm{ml}$, catalog no. ABIN365380, detection range 6.25-400 pg/ml, detection minimum $6.25 \mathrm{pg} / \mathrm{ml}$ ).
Table I. Primer sequences.

\begin{tabular}{|c|c|c|c|}
\hline $\begin{array}{l}\text { Target } \\
\text { gene }\end{array}$ & & $\begin{array}{c}\text { Primers } \\
\text { sequences }\end{array}$ & $\begin{array}{l}\text { Size } \\
\text { (bp) }\end{array}$ \\
\hline \multirow[t]{2}{*}{ c-Fos } & $\mathrm{F}$ & 5'-GGGCATCGGGGATCTTGC-3' & 510 \\
\hline & $\mathrm{R}$ & 5'-GGGCTCTGTCAAC-3' & \\
\hline \multirow[t]{2}{*}{ GFAP } & $\mathrm{F}$ & 5'-GAGAGGAAGGTTGAGTCGCT-3' & 241 \\
\hline & $\mathrm{R}$ & 5'-CGTCTGTGAGGTCTGCAAAC-3' & \\
\hline \multirow[t]{2}{*}{ IBA1 } & $\mathrm{F}$ & 5'-ATGCTGGAGAAACTTGGGGT-3' & 190 \\
\hline & $\mathrm{R}$ & 5'-CAGTTGGCTTCTGGTGTTCT-3' & \\
\hline \multirow[t]{2}{*}{ CGRP } & $\mathrm{F}$ & 5'-ACTGCATCCTGAATATCAGTCTC-3' & 223 \\
\hline & $\mathrm{R}$ & 5'-CAGTTGTACAAGGAAGTCACCTT-3' & \\
\hline \multirow[t]{2}{*}{ PAR2 } & $\mathrm{F}$ & 5'-TGGCAACGACTGGACCTAT-3' & 497 \\
\hline & $\mathrm{R}$ & 5'-TGGGAGCGAAGCAGATGAAG-3' & \\
\hline \multirow[t]{2}{*}{ PKC- $\gamma$} & $\mathrm{F}$ & 5'-TCTTCCCAGAAACCCCACTC-3' & 232 \\
\hline & $\mathrm{R}$ & 5'-AGAACATGGAAGGGAGGTGG-3' & \\
\hline \multirow[t]{2}{*}{ PKA } & $\mathrm{F}$ & 5'-GGCTTCCAACTCCAACGATG-3' & 240 \\
\hline & $\mathrm{R}$ & 5'-GTGTGCTCGATCTGCTTCAG-3' & \\
\hline \multirow[t]{2}{*}{ TRPV1 } & $\mathrm{F}$ & 5'-TGCACAATGGGCAGAATGAC-3' & 151 \\
\hline & $\mathrm{R}$ & 5'-GTCATGTTCCGCCGTTCAAT-3' & \\
\hline \multirow[t]{2}{*}{ GAPDH } & $\mathrm{F}$ & 5'-CCCCCAATGTATCCGTTGTG-3' & 118 \\
\hline & $\mathrm{R}$ & 5'-TAGCCCAGGATGCCCTTTAGT-3' & \\
\hline
\end{tabular}

F, forward; R, reverse; PAR2, proteinase-activated receptor 2.

Quantitative RT-PCR. To analyze c-Fos, GFAP, IBA1 and CGRP mRNA levels, total RNA was isolated from the L4-L5 spinal cord using the TRizol reagent (Invitrogen, Beijing, Mao Jian United Stars Technology Co., Ltd., Beijing, China) according to the manufacturer's instructions. Total RNA $(5 \mu \mathrm{g})$ was reverse transcribed to cDNA with a first-strand cDNA synthesis kit (Invitrogen). Quantitative PCR was performed using a LightCycler system (Roche, Beijing Mao Jian United Stars Technology Co., Ltd.) with SYBR-Green. Each PCR was performed in triplicate to a final solution volume of $20-\mu 1$ : $10 \mu \mathrm{l}$ of SYBR-Green dye, $1 \mu \mathrm{l}$ of diluted cDNA products, $0.2 \mu \mathrm{M}$ of each paired primer and $8.6 \mu \mathrm{l}$ of deionized water. Protocols were as follows: initial denaturation for $5 \mathrm{~min}$ at $95^{\circ} \mathrm{C}$, followed by 35 cycles denaturation for $15 \mathrm{sec}$ at $95^{\circ} \mathrm{C}$, and extension for $30 \mathrm{sec}$ at $56^{\circ} \mathrm{C}$. Last cycle for dissociation of SYBR-Green probe was $15 \mathrm{sec}$ at $95^{\circ} \mathrm{C}, 30 \mathrm{sec}$ at $56^{\circ} \mathrm{C}$, and $15 \mathrm{sec}$ at $95^{\circ} \mathrm{C}$. Primer sequences are shown in Table I. Relative mRNA levels of c-Fos, GFAP, IBA1 and CGRP were normalized to GAPDH.

To analyze PAR2, PKC- $\gamma$, PKA and TRPV1 mRNA levels from rat bones with tumor invasion, total RNA was isolated using a TRIzol reagent and RT-PCRs were performed as above. Primer sequences are shown in Table I.

Western blot assay. To analyze c-Fos, GFAP, IBA1 and CGRP protein levels, total proteins from the L4-L5 spinal cords in various groups were extracted by sonication in RIPA buffer containing protease inhibitors (Roche). Extracted proteins were dialyzed in PBS. After measuring protein content with a BCA protein assay kit (Thermo Scientific, Rockford, IL, 
USA), protein samples with equal amounts of total protein were separated on SDS-PAGE gels and transferred to nitrocellulose (NC) membranes (Millipore). Western blot assay was performed, as previously reported $(16,27,28,31)$. Primary antibodies used in the present study were obtained from Abcam (Cambridge, MA, USA) including anti-c-Fos (phospho T325) (ab27793), anti-GFAP (ab4674), anti-IBA1 (ab107159) and antiCGRP [EPR9670(B)] (ab139264) antibodies. Target protein bands were detected using horseradish peroxidase-conjugated secondary antibodies and visualized by an enhanced chemiluminescence detection system (Beijing Mao Jian United Stars Technology Co., Ltd.). Relative protein expression levels were quantified by ImageQuant ${ }^{\mathrm{TM}}$ LAS 4000 (GE Healthcare) and normalized to GAPDH.

To analyze PAR2, PKC- $\gamma$, PKA and TRPV1 protein levels in rat bones with tumor invasion, total proteins were extracted, quantified and analyzed by western blotting as previously described. Primary antibodies used in experiments were also obtained from Abcam including anti-PKC $\gamma$ (phospho T514) (ab109539), anti-PAR2 (ab180953), anti-PKA $\alpha+\beta$ (catalytic subunits) (phospho T197) (ab5815) and anti-VR1 (ab63083) antibodies.

Statistical analysis. Behavioral data are expressed as mean \pm standard deviation (SD) and analyzed with repeated measures ANOVA, while ELISA data were analyzed by one-way ANOVA followed by Newman-Keuls test. SPSS 13.0 statistical software was used in the present study. $\mathrm{P}<0.05$ was considered to indicate a statistically significant result.

\section{Results}

$X Z P$ treatment reduce nociceptive responses in rats with bone cancer. We first determined the effects of XZP treatments on bone cancer-related nociceptive behavior in bone cancer bearing Wister rats. While constant levels of mechanical thresholds were observed in sham control rats, levels of mechanical thresholds were gradually reduced throughout the observation period in rats in the placebo group (Fig. 1A). In contrast, treatment with different doses of XZP significantly mitigated mechanical allodynia in a dose- and time-dependent manner; although mechanical threshold values were lower than OPG-treated positive controls. Similar PWL patterns were observed in different groups of rats (Fig. 1B). These data indicated that XZP treatment reduced mechanical and thermal nociceptive behavior in rats with bone cancer.

$X Z P$ treatment mitigates bone damage in rats with bone cancer. Next, we examined the effects of XZP treatment on tibia cancer-induced bone structural damage. X-ray images indicated less severe loss of medullary bone and cortical bone erosion were observed in positive control (OPG) rats and XZP-treated rats at various doses at day 21 of post cell inoculation, while full-thickness bicortical bone loss was accompanied by displaced fractures in rats with bone cancer in the placebo group (Fig. 2A). Quantitative analysis revealed that radiological scores in rats that received different doses of XZP were significantly less than the placebo group, yet remained higher than OPG-treated positive controls (Fig. 2B). Quantitative analyses of BMC and BMD revealed that high-dose
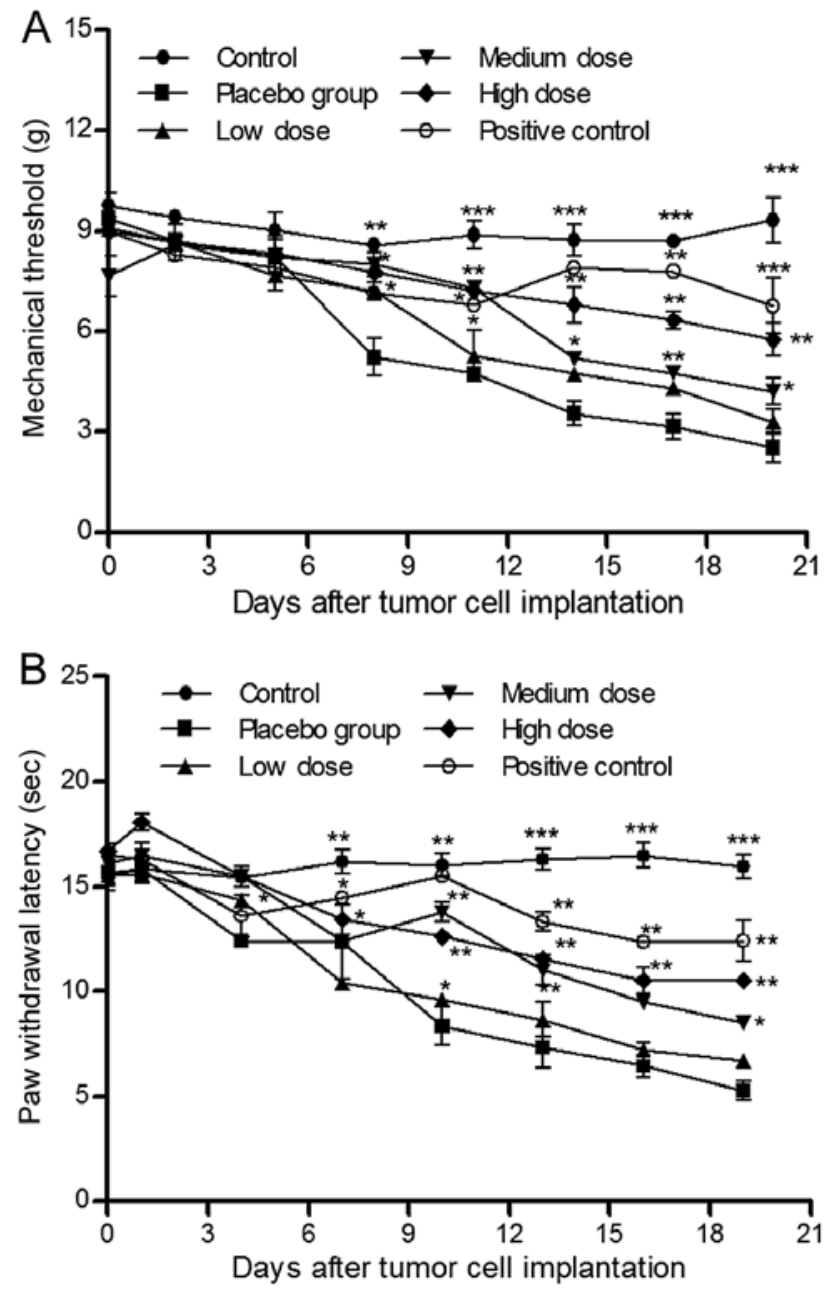

Figure 1. XZP treatment mitigates bone cancer-related nociceptive behavior in rats. Mechanical thresholds were gradually reduced throughout the observation period in rats in the placebo group, and levels of mechanical thresholds were consistent in the sham controls. However, different doses of XZP treatment significantly mitigated mechanical allodynia in a dose- and time-dependent manner; although mechanical threshold values were lower than OPG-treated positive controls (A). Similar paw withdrawal latency (PWL) patterns were observed in different groups of rats (B). Different groups of rats were longitudinally tested for mechanical allodynia and PWL at indicated time points in a blinded manner. Data are expressed as means $\pm \mathrm{SD}$ of individual groups of rats ( $\mathrm{n}=10 /$ group). ${ }^{*} \mathrm{P}<0.05,{ }^{* *} \mathrm{P}<0.01$ and ${ }^{* * * *} \mathrm{P}<0.001$ vs. control group. XZP, Xiaozheng Zhitong Paste.

XZP treatment, similar to OPG, significantly preserved BMC at day 7,14 and 21 post cell inoculation $(\mathrm{P}<0.05, \mathrm{P}<0.01$, Fig. 2C). Furthermore, medium- or high-dose XZP treatment, similar to OPG treatment, significantly mitigated BMD loss at day 7, 14 and 21 post cell inoculation (Fig. 2D). Histological examinations revealed that very few cancer cells invaded into bone tissues in positive controls and in rats treated with different doses of XZP, while a significant number of cancer cells invaded bone tissues and destroyed bone structure in the placebo group (Fig. 2E). Collectively, XZP treatment mitigated cancer invasion-mediated bone damage and structural changes.

XZP treatment inhibits activation of astrocytes and microglial cells in rats with bone cancer. To determine potential mechanisms underlying the action of XZP, we analyzed microglial 

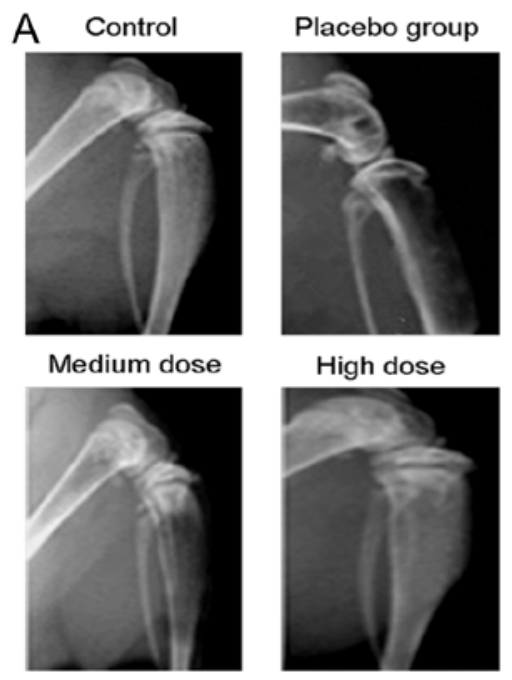

High dose
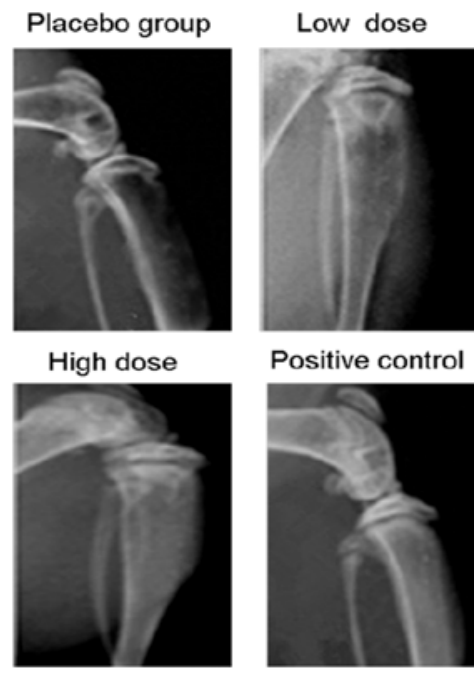

Positive control
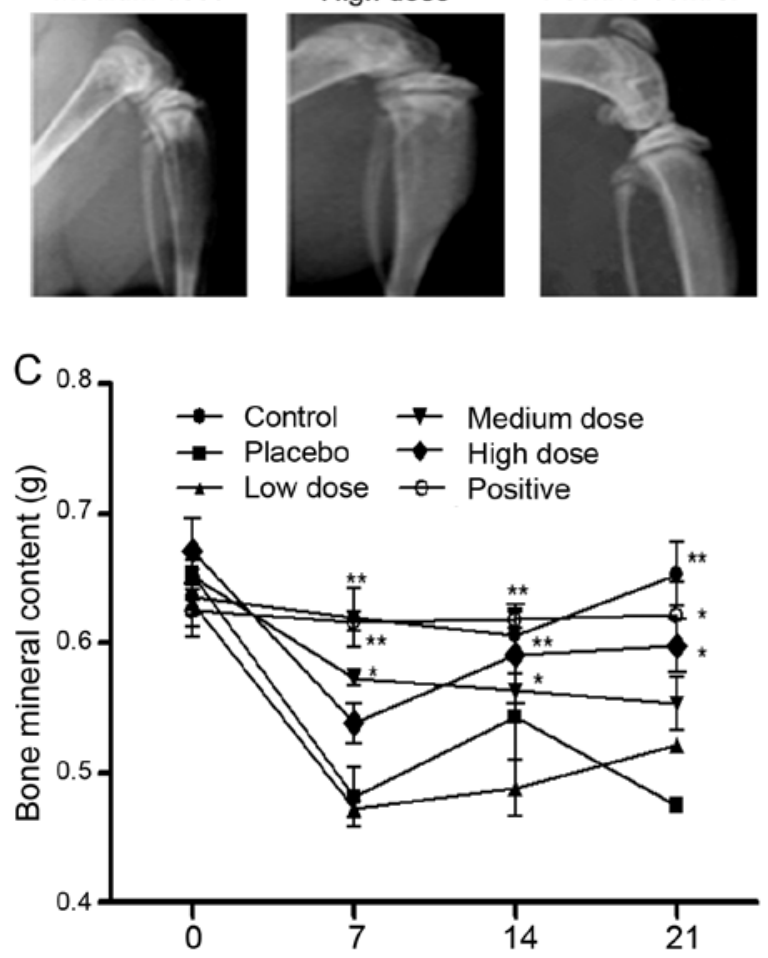

Time post inoculation (days)
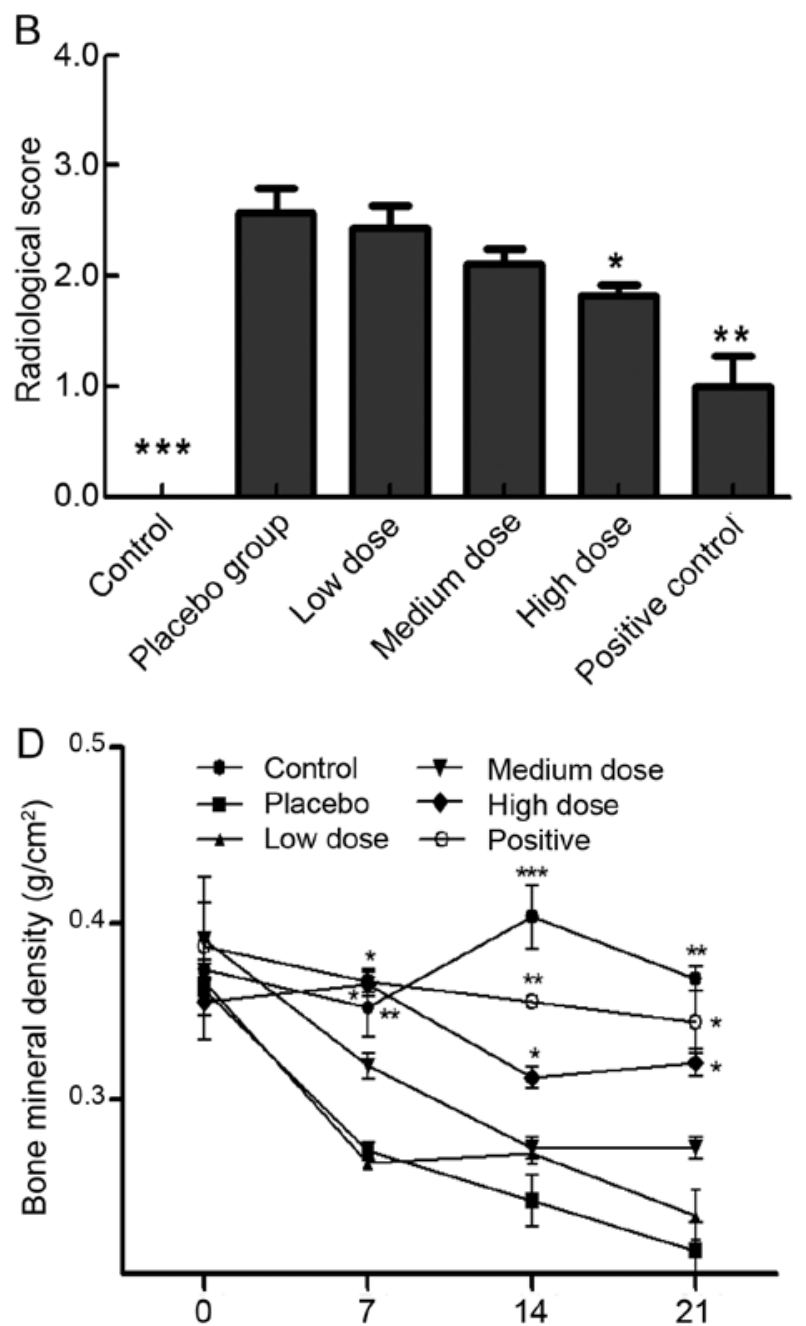

Time post inoculation (days)
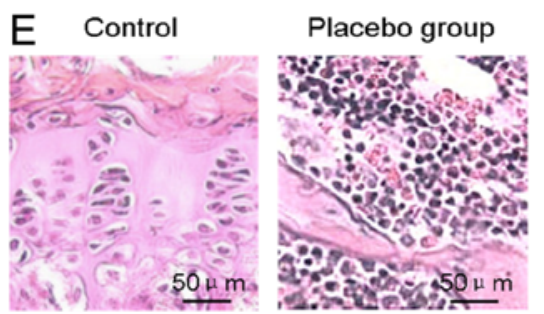

Low dose

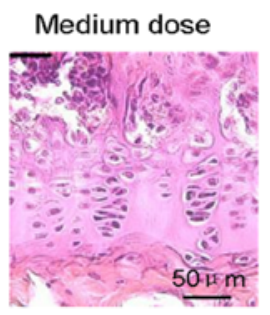

High dose
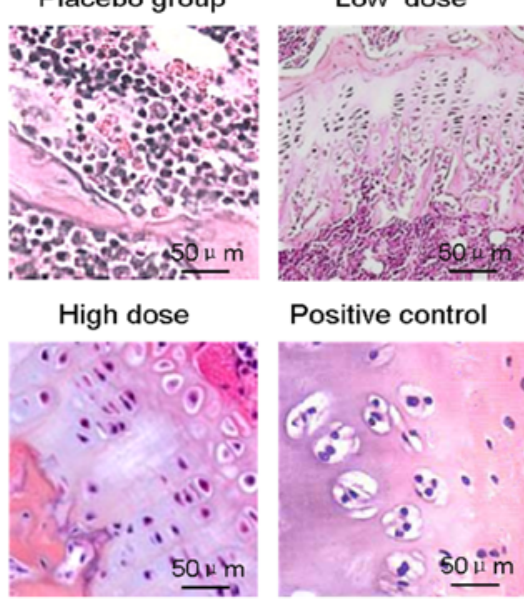

Positive control

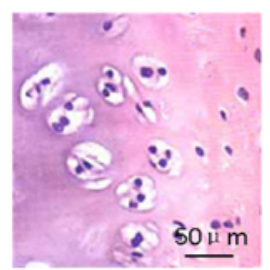

Figure 2. Characterization of bone damage in rats. BMC and BMD values of individual rats were measured by radiology at indicated time points, and bone damage was characterized by X-ray and histology. Radiological scores of tibias of individual rats were calculated. Data are representative images and expressed as means \pm SD of individual groups of rats (n=10/group). (A and B) X-ray analysis of tibia bones and radiological scores of individual groups. (C) BMC. (D) BMD. (E) Histological analyses of tibia bone tissues. ${ }^{*} \mathrm{P}<0.05,{ }^{* *} \mathrm{P}<0.01$ and ${ }^{* * *} \mathrm{P}<0.001$ vs. control group. BMC, bone mineral content; BMD, bone mineral density.

IBA1 and astrocyte GFAP markers, and neurotransmitters c-Fos and CGRP, in the spinal cord of rats (Fig. 3). Significantly increased levels of c-Fos, GFAP, IBA1 and CGRP mRNA transcripts were detected in rats with bone cancer, compared with the sham controls (Fig. 3A); while relative levels of their gene mRNA transcripts were significantly reduced in rats 


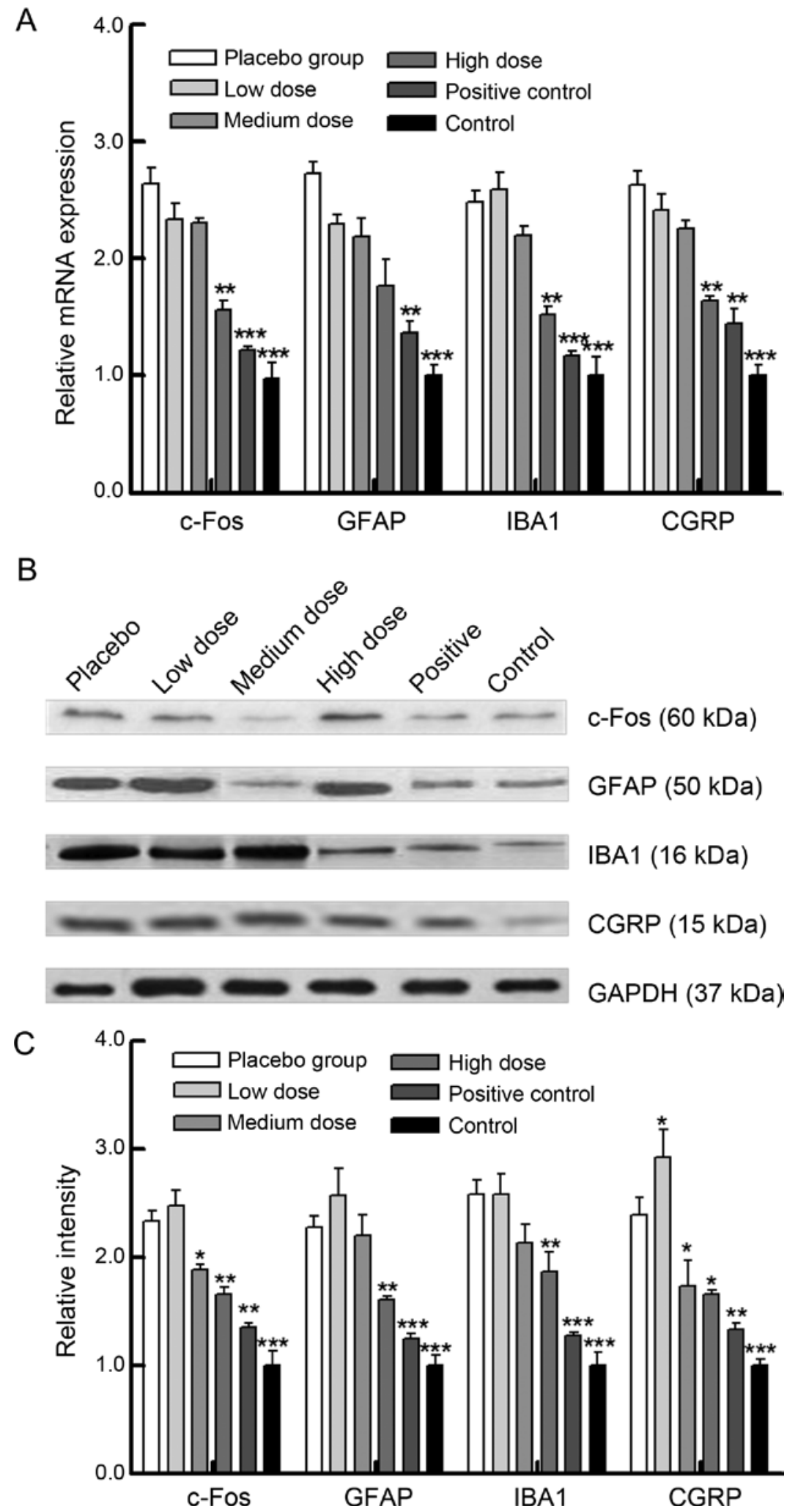

Figure 3. Expressions of microglial IBA1, astrocyte GFAP marker and neurotransmitters c-Fos and CGRP in spinal cord of rats. Relative expression levels of IBA1, GFAP, c-Fos and CGRP in the spinal cord of various groups of rats at indicated time points were determined by quantitative RT-PCR and western blotting assays. Data are representative images and expressed as means \pm SD of individual groups of rats at indicated time points ( $\mathrm{n}=10 / \mathrm{group} / \mathrm{time}$ point). (A) Relative levels of mRNA transcripts. (B) Representative images of western blotting. (C) Quantitative analysis of protein expressions of western blotting. ${ }^{*} \mathrm{P}<0.05$ vs. control group; ${ }^{*} \mathrm{P}<0.05$ vs. placebo group; ${ }^{\wedge} \mathrm{P}<0.05$ vs. positive control group.

treated with XZP, similar to rats that received OPG treatment. A similar pattern was detected when protein expressions in the spinal cord were analyzed (Fig. 3B and C). Thus, XZP treatment inhibited the activation of astrocytes and microglial cells, contributing to its therapeutic effects in rats with bone cancer. 

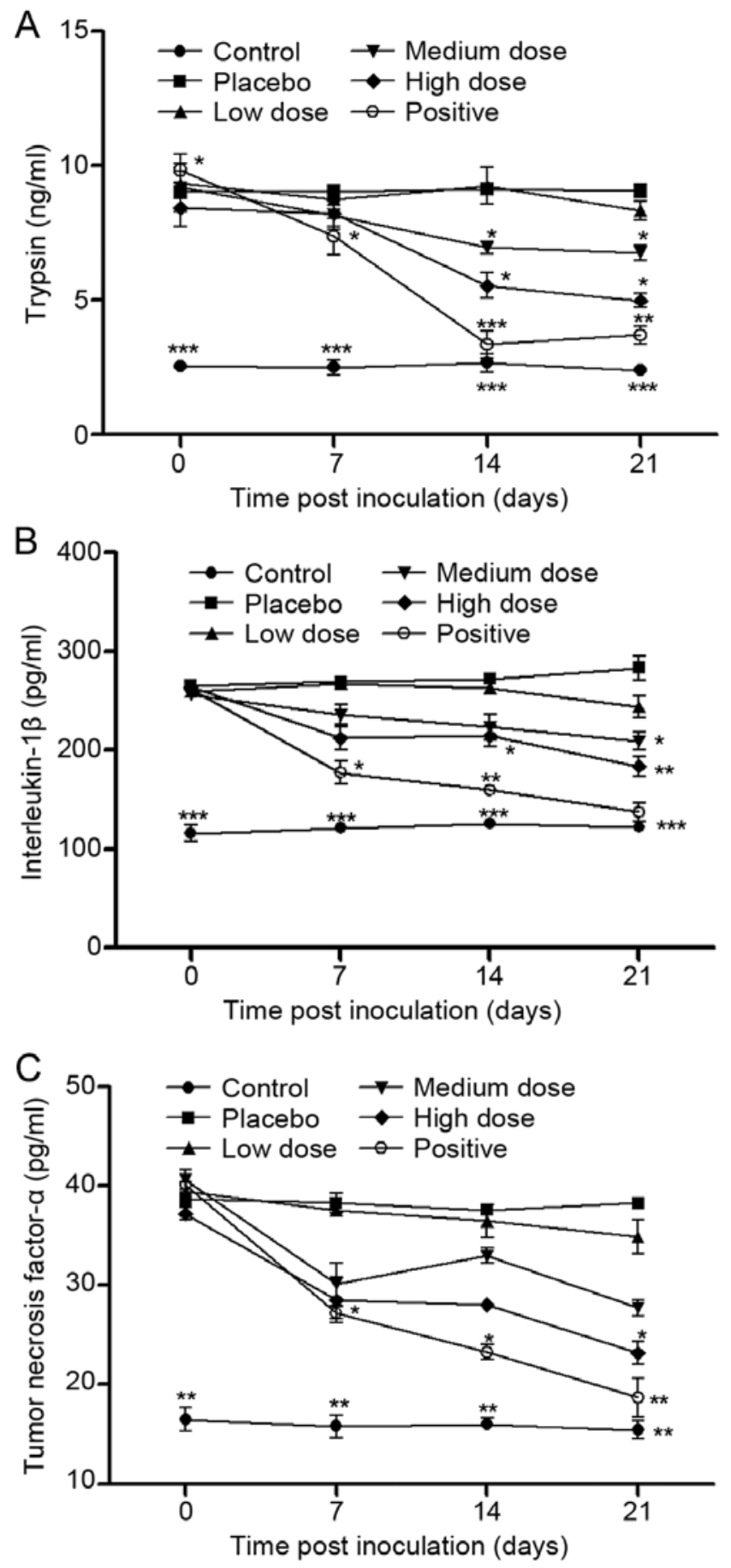

Figure 4. Expression of inflammatory mediator levels in serum of rats. Trypsin, IL-1 $\beta$ and TNF- $\alpha$ serum expression levels of individual rats were measured by ELISA. (A) Trypsin. (B) IL-1 $\beta$. (C) TNF- $\alpha$. * $P<0.05$ vs. control group; ${ }^{\sharp} \mathrm{P}<0.05$ vs. placebo group; ${ }^{\wedge} \mathrm{P}<0.05$ vs. positive control group.

$X Z P$ treatment inhibits the PAR2 signaling pathway in rats with bone cancer. ELISA analysis indicated that upstream levels of the PAR2 signaling pathway including trypsin, TNF- $\alpha$ and IL-1 $\beta$ serum in rats treated with XZP were significantly reduced at day 7,14 or 21 post-inoculation, compared with placebo controls (Fig. 4); and these effects appeared to be dose-dependent. Furthermore, relative downstream levels of PAR2 signaling pathway mediators including PAR2, PKC- $\gamma$, PKA and TRPV1 mRNA transcripts in bone lesions were significantly increased in the rats with bone cancer, compared with the sham controls (Fig. 5A); while relative levels of these gene mRNA transcripts were significantly reduced in the rats that received XZP treatment, similar to rats with OPG treatment. A similar pattern was detected when protein expression was analyzed in bone lesions in rats in the different groups (Fig. 5B and C). Collectively, these data indicate that XZP treatment inhibited the PAR2 signaling pathway in rats with bone cancer, which contributes to the observed antinociceptive effects.

\section{Discussion}

The present study aimed to demonstrate the therapeutic effects of topical XZP treatment in bone cancer pain by establishing a rat model and exploring its underlying mechanism. Our major findings from the present study revealed that various doses of XZP treatment significantly alleviated bone cancer-related nociception; and inhibition of the PAR2 signaling pathway in a dose-dependent manner was most likely the underlying mechanism of action. We anticipate that these results may be beneficial to the development of this TCM for treating bone cancer pain in clinical practice.

Cancer bone metastasis is common and has a devastating impact on the quality of life of patients $(3,37,38)$. Cancer-related bone metastasis cause bone damage and pain, which is particularly difficult to treat $(3,37,38)$. Our previous study has shown that XZP treatment alleviates cancer pain in clinical practice (17). Our results from the present study indicate that XZP treatment alleviated cancer-related bone pain through different mechanisms (39).

Central nervous system (CNS) glia act as immune effector cells in both normal and pathological conditions, playing a vital role in initiating processes of persistent pain states (40-42). Previous studies have shown that early CNS glial response to peripheral nerve injury is predominantly due to the activation of spinal microglia, and that astrocytes subsequently undergo activation and proliferation $(43,44)$. The activation of astrocytes and microglial cells leads to the robust release of proinflammatory cytokines such as IL-1 $\beta$ and TNF- $\alpha(45,46)$. Cytokines are important factors that contribute to the establishment of central sensitization (47). For instance, IL-1 $\beta$ increases NMDAR phosphorylation and NMDAR-mediated intracellular calcium release in sensory neurons (48). TNF- $\alpha$ increased neuronal excitability by stimulating neuronal ion channels $(49,50)$. These proinflammatory cytokines may also activate glial cells, resulting in the amplification of glia-mediated pain-related cascades. The activation of astrocytes and microglial cells, as well as increased activity of proinflammatory cytokines in the spinal cord, are common mechanisms underlying pathological pain in a number of pain syndromes with widely different etiologies, such as peripheral nerve injury, spinal inflammation and bone cancer neuropathy $(40,41,45,51)$.

In the present study, tumor cell implantation caused an increase in microglial IBA1 and astrocyte GFAP markers, and neurotransmitters c-Fos and CGRP; indicating a central sensitization effect. XZP treatment significantly mitigated IBA1, GFAP, c-Fos and CGRP expressions in the spinal cord; and treatment effects appear to be dose-dependent. Our data further supported previous findings; wherein, targeting 
A

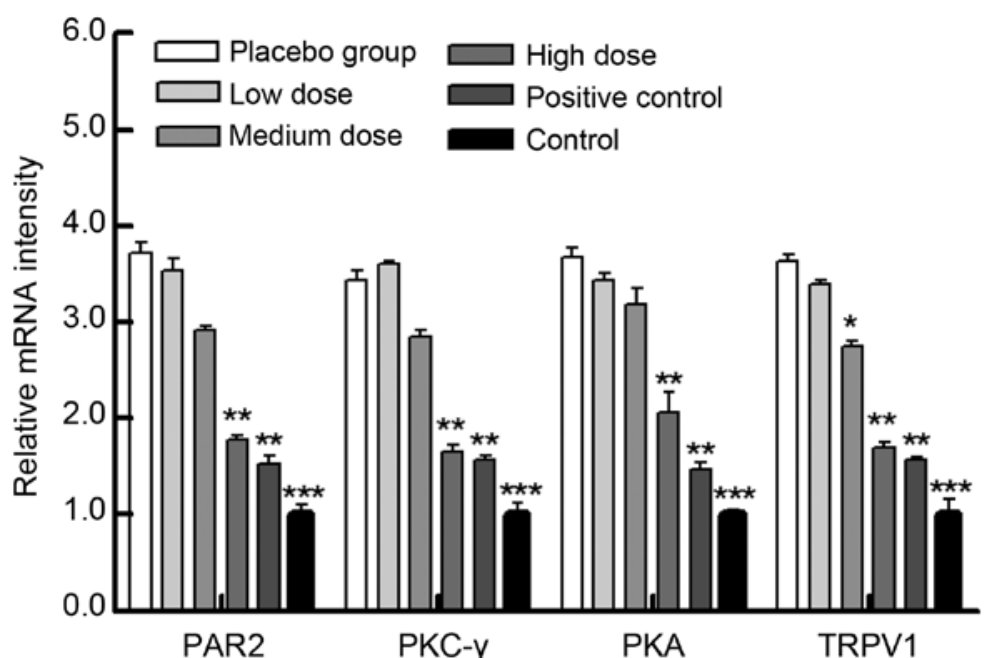

B
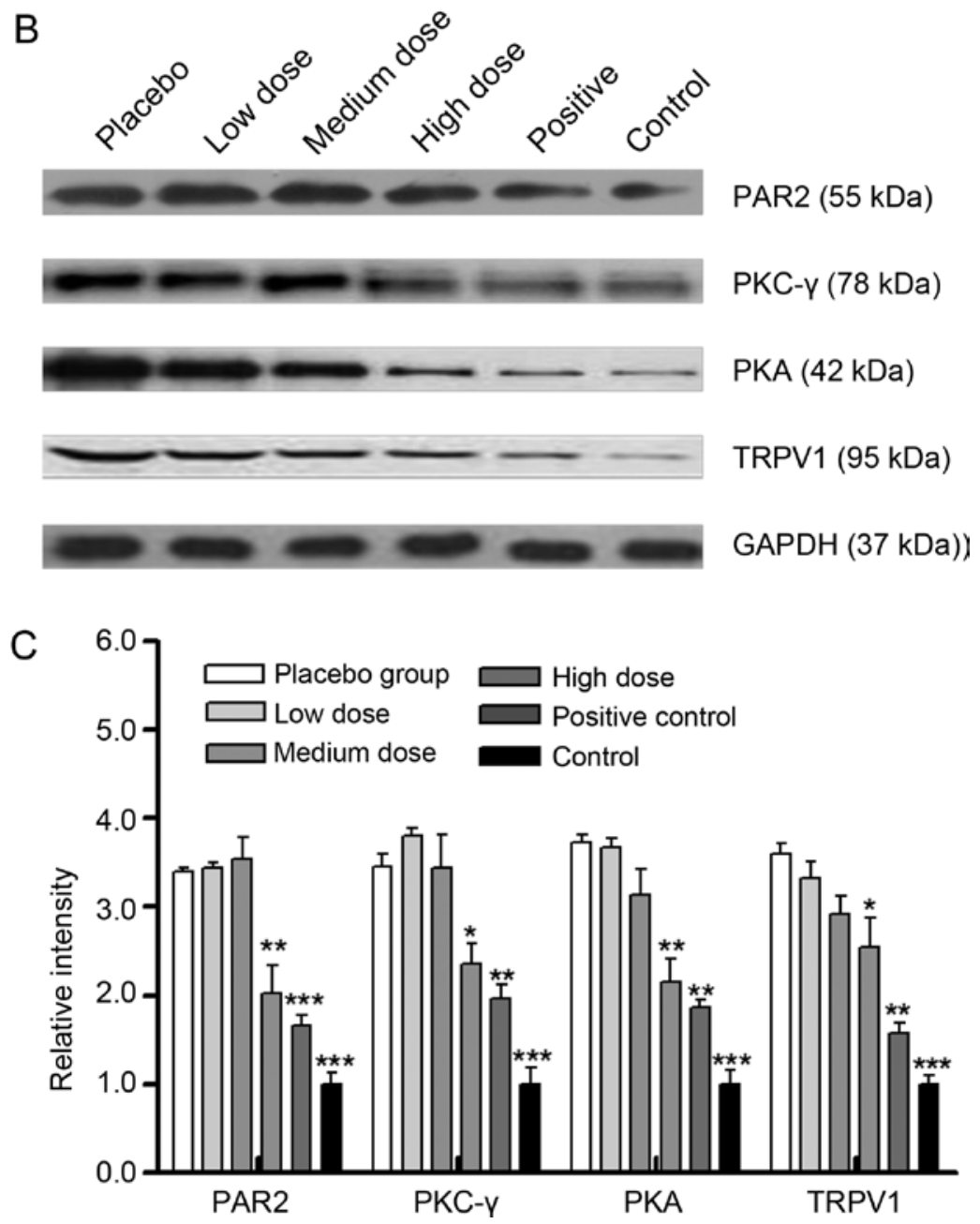

Figure 5. Expression of PAR2 signaling pathway in tibia bone tissues of rats. Relative downstream levels of PAR2 signaling pathway mediators including PAR2, PKC- $\gamma$, PKA and TRPV1 in tibia bone tissues of individual groups of rats at indicated time points were determined by quantitative RT-PCR and western blotting. Data are representative images and expressed as means \pm SD of individual groups of rats at indicated time points (n=10/group/time point). (A) Relative levels of mRNA transcripts. (B) Representative images of western blotting. (C) Quantitative analysis of protein expression measured by western blotting. ${ }^{*} \mathrm{P}<0.05$ vs. control group; ${ }^{*} \mathrm{P}<0.05$ vs. placebo group; ${ }^{\wedge} \mathrm{P}<0.05$ vs. positive control group. $\mathrm{PAR} 2$, proteinase-activated receptor 2.

the PAR2 signaling pathway inhibits cancer-induced bone pain $(34,52,53)$.

Proteolytic activity is critical to carcinogenesis and cancer microenvironment is associated with various proteases. Cancer-associated serine proteases, such as trypsin, are released during the early stages of tissue invasion and may directly activate PAR2 on nociceptive afferents; resulting in acute pain that is spontaneous and exacerbated during function. PAR2 activation may also sensitize other nociceptive receptors such as PKA, PKC- $\gamma$ and TRPV1 $(26-33,54,55)$. 


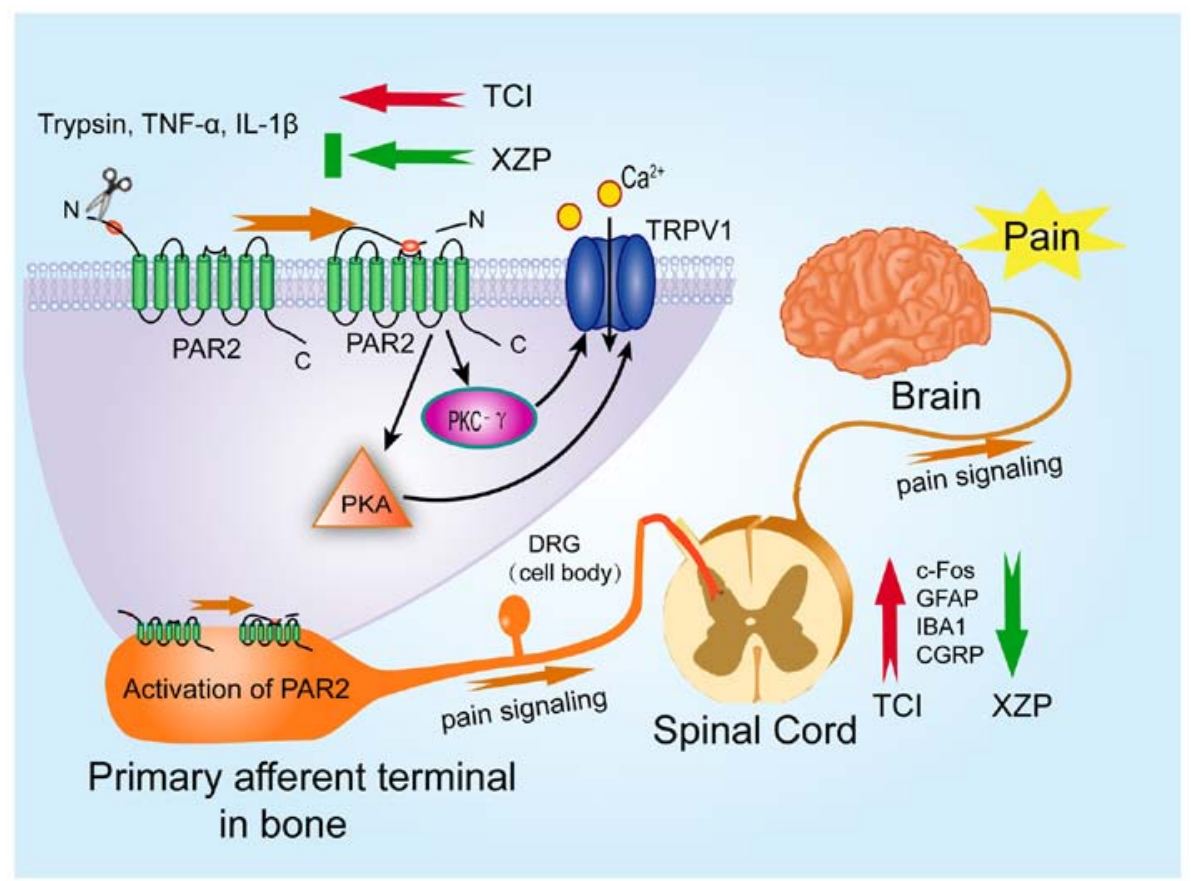

Figure 6. Proposed model of mechanism of action for Xiaozheng Zhitong Paste (XZP) treatment on bone cancer pain. Tumor cell implantation (TCI) induces release of trypsin, IL-1 $\beta$ and TNF- $\alpha$ in the serum. Trypsin activates PAR2 on primary afferent terminals in tumor-bearing tibias. Activation of PAR2 results in the increase of PKA, PKC- $\gamma$ and TRPV1 levels, which induce enhanced influx of $\mathrm{Ca}^{2+}$ ions, and elevate the release of IBA1, GFAP, c-Fos and CGRP expressions in the spinal cord; resulting in an enhanced transmission of pain signaling and nociceptive behaviors. XZP treatment significantly mitigated the expression of IBA1, GFAP, c-Fos and CGRP in the spinal cord and significantly inhibit trypsin, TNF- $\alpha$ and IL-1 $\beta$ serum levels. Furthermore, relative downstream levels of PAR2 signaling pathway mediators including PAR2, PKC- $\gamma$, PKA and TRPV1 in bone lesions were significantly reduced after XZP treatment. PAR2, proteinase-activated receptor 2 .

With continued cancer cell proliferation and mediator release, nociceptive afferents may be persistently activated or sensitized and consequently maintain a persistent pain state. It has been well demonstrated that PAR2 is upregulated following various inflammatory and ischemic insults $(56,57)$. Mediators, such as trypsin, TNF- $\alpha$ and IL- $1 \beta$ upregulated PAR2 (58). PAR2 upregulation in dorsal root ganglia has been associated with thermal hyperalgesia following chronic pancreatitis (59) and cAMP-dependent neuronal hyperexcitability following chronic nerve compression (60). Additionally, cancer-induced PAR2 upregulation in trigeminal ganglions similarly alters pain processing and mediate the progression to chronic cancer pain (34). The complete absence of cancer-induced functional allodynia in mice lacking PAR2 clearly demonstrates the critical involvement of PAR2 in acute and chronic cancer pain (34).

In the present study, we found that XZP treatment significantly mitigated trypsin, TNF- $\alpha$ and IL- $1 \beta$ serum levels in a dose-dependent manner. Furthermore, relative downstream levels of PAR2 signaling pathway mediators including PAR2, PKC- $\gamma$, PKA and TRPV1 mRNA transcripts and protein expression in bone lesions were significantly reduced in rats that received XZP treatment, similar to rats with OPG treatment. These findings further supported the notion that targeting the PAR2 signaling pathway inhibits cancer-induced bone pain $(34,52)$.

In summary, our data demonstrated that XZP treatment mitigated bone cancer-related nociceptive behavior, and inhibited peripheral and central sensitization by inhibiting the PAR2 signaling pathway (Fig. 6). Our data provides new insights into the molecular mechanisms underlying the pathogenesis of bone cancer pain and mechanism of action of XZP in alleviating bone cancer pain in clinical practice. Our findings may be beneficial in designing new therapeutic agents for alleviating bone cancer pain.

\section{Acknowledgements}

This study was partially supported by the National Natural Science Foundation of China (grant nos. 81302961, 81273718 and 81202931).

\section{References}

1. Sabino MA and Mantyh PW: Pathophysiology of bone cancer pain. J Support Oncol 3: 15-24, 2005.

2. Mercadante S: Malignant bone pain: Pathophysiology and treatment. Pain 69: 1-18, 1997.

3. Coleman RE: Clinical features of metastatic bone disease and risk of skeletal morbidity. Clin Cancer Res 12: 6243s-6249s, 2006.

4. Chow E, Zeng L, Salvo N, Dennis K, Tsao M and Lutz S: Update on the systematic review of palliative radiotherapy trials for bone metastases. Clin Oncol 24: 112-124, 2012.

5. Portenoy RK, Payne D and Jacobsen P: Breakthrough pain: Characteristics and impact in patients with cancer pain. Pain 81: 129-134, 1999.

6. Chan FK: Primer: Managing NSAID-induced ulcer complications-balancing gastrointestinal and cardiovascular risks. Nat Clin Pract Gastroenterol Hepatol 3: 563-573, 2006.

7. Lapeyre-Mestre M, de Castro AM, Bareille MP, Del Pozo JG, Requejo AA, Arias LM, Montastruc JL and Carvajal A: Non-steroidal anti-inflammatory drug-related hepatic damage in France and Spain: Analysis from national spontaneous reporting systems. Fundam Clin Pharmacol 20: 391-395, 2006. 
8. Schneider V, Lévesque LE, Zhang B, Hutchinson T and Brophy JM: Association of selective and conventional nonsteroidal antiinflammatory drugs with acute renal failure: A population-based, nested case-control analysis. Am J Epidemiol 164: 881-889, 2006.

9. Michaelson MD and Smith MR: Bisphosphonates for treatment and prevention of bone metastases. J Clin Oncol 23: 8219-8224, 2005.

10. Wong R and Wiffen PJ: Bisphosphonates for the relief of pain secondary to bone metastases. Cochrane Database Syst Rev (2) CD002068, 2002.

11. Wang J, Zhang R, Dong C, Jiao L, Xu L, Liu J, Wang Z, Mao Ying QL, Fong $\mathrm{H}$ and Lao L: Topical treatment with Tong-Luo-San-Jie gel alleviates bone cancer pain in rats. J Ethnopharmacol 143: 905-913, 2012.

12. Bao Y, Kong X, Yang L, Liu R, Shi Z, Li W, Hua B and Hou W: Complementary and alternative medicine for cancer pain: An overview of systematic reviews. Evid Based Complement Alternat Med 2014: 170396, 2014.

13. Yanju B, Yang L, Hua B, Hou W, Shi Z, Li W, Li C, Chen C, Liu R, Qin Y, et al: A systematic review and meta-analysis on the use of traditional Chinese medicine compound kushen injection for bone cancer pain. Support Care Cancer 22: 825-836, 2014.

14. Xu L, Lao LX, Ge A, Yu S, Li J and Mansky PJ: Chinese herbal medicine for cancer pain. Integr Cancer Ther 6: 208-234, 2007.

15. Gözüm S, Tezel A and Koc M: Complementary alternative treatments used by patients with cancer in eastern Turkey. Cancer Nurs 26: 230-236, 2003.

16. Bao Y, Gao Y, Du M, Hou W, Yang L, Kong X, Zheng H, Li W and Hua B: Topical treatment with Xiaozheng Zhitong Paste (XZP) alleviates bone destruction and bone cancer pain in a rat model of prostate cancer-induced bone pain by modulating the RANKL/RANK/OPG signaling. Evid Based Complement Alternat Med 2015: 215892, 2015.

17. Bao YJ, Hua BJ, Hou W, Lin HS, Zhang XB and Yang GX: Alleviation of cancerous pain by external compress with Xiaozheng Zhitong Paste. Chin J Integr Med 16: 309-314, 2010.

18. van den Beuken-van Everdingen MH, de Rijke JM, Kessels AG, Schouten HC, van Kleef M and Patijn J: Prevalence of pain in patients with cancer: A systematic review of the past 40 years. Ann Oncol 18: 1437-1449, 2007.

19. Mantyh P: Bone cancer pain: Causes, consequences, and therapeutic opportunities. Pain 154 (Suppl 1): S54-S62, 2013.

20. Mao-Ying QL, Wang XW, Yang CJ, Li X, Mi WL, Wu GC and Wang YQ: Robust spinal neuroinflammation mediates mechanical allodynia in Walker 256 induced bone cancer rats. Mol Brain 5: 16, 2012.

21. Wang XW, Hu S, Mao-Ying QL, Li Q, Yang CJ, Zhang H, Mi WL, Wu GC and Wang YQ: Activation of c-jun N-terminal kinase in spinal cord contributes to breast cancer induced bone pain in rats. Mol Brain 5: 21, 2012.

22. Wang XW, Li TT, Zhao J, Mao-Ying QL, Zhang H, Hu S, Li Q, Mi WL, Wu GC, Zhang YQ, et al: Extracellular signal-regulated kinase activation in spinal astrocytes and microglia contributes to cancer-induced bone pain in rats. Neuroscience 217: 172-181, 2012.

23. Ke C, Li C, Huang X, Cao F, Shi D, He W, Bu H, Gao F, Cai T, Hinton AO Jr, et al: Protocadherin 20 promotes excitatory synaptogenesis in dorsal horn and contributes to bone cancer pain. Neuropharmacology 75: 181-190, 2013.

24. Yanagisawa Y, Furue H, Kawamata T, Uta D, Yamamoto J, Furuse S, Katafuchi T, Imoto K, Iwamoto Y and Yoshimura M: Bone cancer induces a unique central sensitization through synaptic changes in a wide area of the spinal cord. Mol Pain 6: $38,2010$.

25. Rothmeier AS and Ruf W: Protease-activated receptor 2 signaling in inflammation. Semin Immunopathol 34: 133-149, 2012.

26. Bao Y, Hou W and Hua B: Protease-activated receptor 2 signalling pathways: A role in pain processing. Expert Opin Ther Targets 18: 15-27, 2014.

27. Bao Y, Hou W, Liu R, Gao Y, Kong X, Yang L, Shi Z, Li W, Zheng H, Jiang S, et al: PAR2-mediated upregulation of BDNF contributes to central sensitization in bone cancer pain. Mol Pain 10: 28, 2014.

28. Bao Y, Gao Y, Hou W, Yang L, Kong X, Zheng H, Li C and Hua B: Engagement of signaling pathways of protease-activated receptor 2 and $\mu$-opioid receptor in bone cancer pain and morphine tolerance. Int J Cancer: Feb 24, 2015 (Epub ahead of print). doi: $10.1002 / \mathrm{ijc} .29497$
29. Bao Y, Gao Y, Yang L, Kong X, Zheng H, Hou W and Hua B: New insights into protease-activated receptor 4 signaling pathways in the pathogenesis of inflammation and neuropathic pain: A literature review. Channels 9: 5-13, 2015.

30. Bao Y, Hou W, Yang L, Kong X, Du M, Zheng H, Gao Y and Hua B: Protease-activated receptor 2 antagonist potentiates analgesic effects of systemic morphine in a rat model of bone cancer pain. Reg Anesth Pain Med 40: 158-165, 2015.

31. Bao Y, Hou W, Yang L, Liu R, Gao Y, Kong X, Shi Z, Li W, Zheng H, Jiang S, et al: Increased expression of protease-activated receptor 2 and 4 within dorsal root ganglia in a rat model of bone cancer pain. J Mol Neurosci 55: 706-714, 2015.

32. Bao Y, Hua B, Hou W, Shi Z, Li W, Li C, Chen C, Liu R and Qin Y: Involvement of protease-activated receptor 2 in nociceptive behavior in a rat model of bone cancer. J Mol Neurosci 52: 566-576, 2014.

33. Hua B, Gao Y, Kong X, Yang L, Hou W and Bao Y: New insights of nociceptor sensitization in bone cancer pain. Expert Opin Ther Targets 19: 227-243, 2015.

34. Liu S, Liu YP, Yue DM and Liu GJ: Protease-activated receptor 2 in dorsal root ganglion contributes to peripheral sensitization of bone cancer pain. Eur J Pain 18: 326-337, 2014.

35. Zimmermann M: Ethical guidelines for investigations of experimental pain in conscious animals. Pain 16: 109-110, 1983.

36. Lamoureux F, Baud'huin M, Rodriguez Calleja L, Jacques C, Berreur M, Rédini F, Lecanda F, Bradner JE, Heymann D and Ory B: Selective inhibition of BET bromodomain epigenetic signalling interferes with the bone-associated tumour vicious cycle. Nat Commun 5: 3511, 2014.

37. Coleman RE: Metastatic bone disease: Clinical features, pathophysiology and treatment strategies. Cancer Treat Rev 27: 165-176, 2001.

38. DePuy V, Anstrom KJ, Castel LD, Schulman KA, Weinfurt KP and Saad F: Effects of skeletal morbidities on longitudinal patient-reported outcomes and survival in patients with metastatic prostate cancer. Support Care Cancer 15: 869-876, 2007.

39. Paqueron X, Conklin D and Eisenach JC: Plasticity in action of intrathecal clonidine to mechanical but not thermal nociception after peripheral nerve injury. Anesthesiology 99: 199-204, 2003.

40. Gosselin RD, Suter MR, Ji RR and Decosterd I: Glial cells and chronic pain. Neuroscientist 16: 519-531, 2010.

41. Nakagawa $T$ and Kaneko S: Spinal astrocytes as therapeutic targets for pathological pain. J Pharmacol Sci 114: 347-353, 2010.

42. Schomberg D and Olson JK: Immune responses of microglia in the spinal cord: Contribution to pain states. Exp Neurol 234: 262-270, 2012.

43. Romero-Sandoval A, Chai N, Nutile-McMenemy $\mathrm{N}$ and Deleo JA: A comparison of spinal Ibal and GFAP expression in rodent models of acute and chronic pain. Brain Res 1219: 116-126, 2008

44. Tanga FY, Raghavendra V and DeLeo JA: Quantitative real-time RT-PCR assessment of spinal microglial and astrocytic activation markers in a rat model of neuropathic pain. Neurochem Int 45: 397-407, 2004.

45. Hald A, Nedergaard S, Hansen RR, Ding M and Heegaard AM: Differential activation of spinal cord glial cells in murine models of neuropathic and cancer pain. Eur J Pain 13: 138-145, 2009.

46. Milligan ED and Watkins LR: Pathological and protective roles of glia in chronic pain. Nat Rev Neurosci 10: 23-36, 2009.

47. Kawasaki Y, Zhang L, Cheng JK and Ji RR: Cytokine mechanisms of central sensitization: Distinct and overlapping role of interleukin-1beta, interleukin-6, and tumor necrosis factor-alpha in regulating synaptic and neuronal activity in the superficial spinal cord. J Neurosci 28: 5189-5194, 2008.

48. Viviani B, Bartesaghi S, Gardoni F, Vezzani A, Behrens MM, Bartfai T, Binaglia M, Corsini E, Di Luca M, Galli CL, et al: Interleukin-1beta enhances NMDA receptor-mediated intracellular calcium increase through activation of the Src family of kinases. J Neurosci 23: 8692-8700, 2003.

49. Dolga AM, Granic I, Blank T, Knaus HG, Spiess J, Luiten PG, Eisel UL and Nijholt IM: TNF-alpha-mediates neuroprotection against glutamate-induced excitotoxicity via NF-kappaB-dependent up-regulation of $\mathrm{K}_{\mathrm{Ca}} 2.2$ channels. J Neurochem 107: 1158-1167, 2008.

50. Riazi K, Galic MA, Kuzmiski JB, Ho W, Sharkey KA and Pittman QJ: Microglial activation and TNFalpha production mediate altered CNS excitability following peripheral inflammation. Proc Natl Acad Sci USA 105: 17151-17156, 2008. 
51. Ren BX, Gu XP, Zheng YG, Liu CL, Wang D, Sun YE and Ma ZL: Intrathecal injection of metabotropic glutamate receptor subtype 3 and 5 agonist/antagonist attenuates bone cancer pain by inhibition of spinal astrocyte activation in a mouse model. Anesthesiology 116: 122-132, 2012.

52. Lam DK, Dang D, Zhang J, Dolan JC and Schmidt BL: Novel animal models of acute and chronic cancer pain: A pivotal role for PAR2. J Neurosci 32: 14178-14183, 2012.

53. Liu S, Liu YP, Song WB and Song XJ: EphrinB-EphB receptor signaling contributes to bone cancer pain via Toll-like receptor and proinflammatory cytokines in rat spinal cord. Pain 154: 2823-2835, 2013

54. Dai Y, Moriyama T, Higashi T, Togashi K, Kobayashi K, Yamanaka H, Tominaga M and Noguchi K: Proteinase-activated receptor 2-mediated potentiation of transient receptor potential vanilloid subfamily 1 activity reveals a mechanism for proteinaseinduced inflammatory pain. J Neurosci 24: 4293-4299, 2004.

55. Grant AD, Cottrell GS, Amadesi S, Trevisani M, Nicoletti P, Materazzi S, Altier C, Cenac N, Zamponi GW, Bautista-Cruz F, et al: Protease-activated receptor 2 sensitizes the transient receptor potential vanilloid 4 ion channel to cause mechanical hyperalgesia in mice. J Physiol 578: 715-733, 2007.
56. Nystedt S, Ramakrishnan V and Sundelin J: The proteinaseactivated receptor 2 is induced by inflammatory mediators in human endothelial cells. Comparison with the thrombin receptor. J Biol Chem 271: 14910-14915, 1996.

57. Striggow F, Riek-Burchardt M, Kiesel A, Schmidt W, HenrichNoack P, Breder J, Krug M, Reymann KG and Reiser G: Four different types of protease-activated receptors are widely expressed in the brain and are up-regulated in hippocampus by severe ischemia. Eur J Neurosci 14: 595-608, 2001.

58. Ritchie E, Saka M, Mackenzie C, Drummond R, WheelerJones C, Kanke T and Plevin R: Cytokine upregulation of proteinase-activated-receptors 2 and 4 expression mediated by p38 MAP kinase and inhibitory kappa B kinase beta in human endothelial cells. Br J Pharmacol 150: 1044-1054, 2007.

59. Zhang W, Gao J, Zhao T, Wei L, Wu W, Bai Y, Zou D and Li Z: Proteinase-activated receptor 2 mediates thermal hyperalgesia and is upregulated in a rat model of chronic pancreatitis. Pancreas 40: 300-307, 2011

60. Huang ZJ, Li HC, Cowan AA, Liu S, Zhang YK and Song XJ: Chronic compression or acute dissociation of dorsal root ganglion induces cAMP-dependent neuronal hyperexcitability through activation of PAR2. Pain 153: 1426-1437, 2012. 